\title{
Neutrophils Use Both Shared and Distinct Mechanisms to Adhere to Selectins under Static and Flow Conditions
}

\author{
Kamala D. Patel, * Kevin L. Moore, ${ }^{* \|}$ Matthias U. Nollert, ' and Rodger P. McEver*\$\$ \\ Departments of ${ }^{*}$ Medicine and ${ }^{\ddagger}$ Biochemistry and Molecular Biology, ${ }^{\S} W . K$. Warren Medical Research Institute, University of \\ Oklahoma Health Sciences Center, the "Cardiovascular Biology Research Program, Oklahoma Medical Research Foundation, \\ Oklahoma City, Oklahoma 73104; and the 'School of Chemical Engineering and Materials Science, University of Oklahoma, \\ Norman, Oklahoma 73109
}

\begin{abstract}
Both P-selectin glycoprotein ligand-1 (PSGL-1) and L-selectin are localized on the microvilli of neutrophils and have been implicated in the attachment of neutrophils to P-selectin or E-selectin. We directly compared the attachment and rolling of neutrophils on P-selectin and E-selectin under flow, with emphasis on the functions of PSGL-1 and Lselectin. Flowing neutrophils attached more avidly and rolled at lower velocities on P-selectin than on E-selectin at matched densities. Studies with purified molecules indicated that P-selectin and E-selectin bound to a related site on PSGL-1 that overlapped the epitope for the anti-PSGL-1 mAb PL1. E-selectin bound with lower affinity than P-selectin to this site and also bound to an additional site(s) on PSGL-1. PL1 abolished adhesion of neutrophils to P-selectin under shear or static conditions, whereas DREG-56, a mAb to L-selectin, had no effect on adhesion to P-selectin. PL1 inhibited attachment of neutrophils to E-selectin under flow but not static conditions. DREG-56 also inhibited attachment of flowing neutrophils to E-selectin, and a combination of DREG-56 and PL1 nearly eliminated attachment to Eselectin under flow. These data suggest that PSGL-1 functions cooperatively with $L$-selectin to mediate optimal attachment of flowing neutrophils to E-selectin but not to $P$ selectin. Neutrophils attach more efficiently and with greater strength to P-selectin, perhaps because of the higher affinity of P-selectin for the PL1-defined site on PSGL-1. (J. Clin. Invest. 1995. 96:1887-1896.) Key words: selectin • leukocyte rolling • cell adhesion molecules • inflammation • neutrophils
\end{abstract}

\section{Introduction}

The selectins are a group of three $\mathrm{Ca}^{2+}$-dependent lectins that mediate the initial attachment and rolling of leukocytes on the vessel wall in the presence of the shear forces found in postcapillary venules (for reviews see references $1-3$ ). Selectin-medi-

Address correspondence to Dr. Rodger P. McEver, Department of Medicine, University of Oklahoma Health Science Center, 825 N.E. 13th Street, Oklahoma City, OK 73104-5073. Phone: 405-271-6480; FAX: 405-271-3137.

Received for publication 30 March 1995 and accepted in revised form 20 June 1995.

J. Clin. Invest.

(C) The American Society for Clinical Investigation, Inc.

$0021-9738 / 95 / 10 / 1887 / 10 \quad \$ 2.00$

Volume 96, October 1995, 1887-1896 ated rolling of neutrophils is followed by juxtacrine activation of $\beta 2$ integrins, which promotes stable attachment and then emigration of neutrophils into tissues at sites of acute inflammation (4). Rolling of lymphocytes is also mediated by selectins and, under some circumstances, by $\alpha 4$ integrins (5-9).

Each selectin has an $\mathrm{NH}_{2}$-terminal carbohydrate-recognition domain characteristic of $\mathrm{Ca}^{2+}$-dependent lectins, followed by an EGF-like domain, a series of short consensus repeats, a transmembrane domain, and a cytoplasmic tail. L-selectin, found on circulating leukocytes, binds to inducible ligands on postcapillary venules and constitutive ligands on high endothelial venules of lymph nodes. E-selectin, expressed transiently by cytokine-activated endothelial cells, binds to ligands on myeloid cells and subsets of lymphocytes. P-selectin, stored in the membranes of secretory granules in platelets and endothelial cells, is rapidly redistributed to the cell surface in response to agonists such as thrombin, histamine, and oxygen radicals, where it binds to ligands on myeloid cells and subsets of lymphocytes.

In a flowing environment, selectins must rapidly form bonds with their ligands to facilitate attachment of leukocytes and then rapidly release these bonds to allow rolling. Identification of the physiologically relevant cell surface ligands for the selectins is critical for understanding the molecular basis for leukocyte attachment and rolling under shear forces. The selectins bind weakly to sialylated, fucosylated, and, in some cases, sulfated oligosaccharides (10). The prototype of these structures is sialyl Lewis $\mathrm{x}\left(\mathrm{sLe}^{\mathrm{x}}\right){ }^{1}$ a terminal tetrasaccharide attached to many glycoproteins and glycolipids on human myeloid cells. In extracts of target cells, however, selectins bind with higher affinity and/or avidity to oligosaccharides on a limited number of glycoproteins. Some of these macromolecules are sialomucins with clustered, sialylated O-linked glycans (11-15). Other glycoproteins display primarily $\mathrm{N}$-linked oligosaccharides $(16,17)$ or have carbohydrate chains that are less well characterized (18). Neutrophil L-selectin, which displays $\operatorname{sLe}^{\mathrm{x}}$, has been proposed as a major ligand for $\mathrm{E}$ - and $\mathrm{P}$-selectin in part because it is localized on the tips of microvilli (19). In solution E- and P-selectin do not bind detectably to L-selectin $(20,21)$, although some mAbs to L-selectin inhibit rolling of neutrophils on E- or P-selectin (22-24). A recent study reported that Lselectin is required for the initial attachment of neutrophils to E-selectin under shear forces, whereas other unidentified ligands mediate the subsequent rolling of neutrophils on E-selectin (22).

We have developed two IgG mAbs (PL1 and PL2) to P-

1. Abbreviations used in this paper: $\mathrm{CHO}$ cells, Chinese hamster ovary cells; OSGE, $O$-sialoglycoprotein endopeptidase; PSGL-1, P-selectin glycoprotein ligand-1; sES, soluble E-selectin; $s L e^{x}$, sialyl Lewis $\mathrm{x}$ (Gal $\beta 1-4$ [Fuc $\alpha 1-3]$ GlcNAc); sPS, soluble P-selectin. 
selectin glycoprotein ligand-1 (PSGL-1), a sialomucin on human leukocytes that binds with high affinity/avidity to P-selectin (25). PL1, but not PL2, abolishes binding of ${ }^{125}$ I-PSGL-1 to immobilized P-selectin, binding of fluid-phase P-selectin to leukocytes, and adhesion of neutrophils to P-selectin surfaces under both static and shear conditions. These data establish that P-selectin must form bonds with PSGL-1 in order for neutrophils to attach to and roll on P-selectin under physiologically relevant shear stresses, even though PSGL-1 is only one of many macromolecules on the neutrophil surface that display sLe $^{x}$. Significantly, PSGL-1, like L-selectin, is concentrated on the tips of microvilli, which may enhance its adhesive function (25).

PSGL-1 is a homodimer of two disulfide-linked subunits with relative molecular masses of 120,000. Each subunit displays at most three N-linked glycans, but many clustered, sialylated O-linked glycans, including poly- $N$-acetyllactosamine that carry $\operatorname{sLe}^{\mathrm{x}}(11)$. Although sialylation $(11,26)$ and fucosylation (12) of the O-linked glycans are required for recognition by Pselectin, the structural basis for high-affinity binding has not been defined. The ability of Fab fragments of the PL1 antibody to inhibit binding of PSGL-1 to P-selectin suggests that a small region on PSGL-1 near the PL1 epitope may constitute the critical recognition site. PSGL-1 also binds to E-selectin (11, $12,16)$. Whether PSGL-1 participates in the rolling of neutrophils on E-selectin under shear stresses has not been established.

Neutrophils may attach to and roll differently on P- and Eselectin if the selectins bind to different ligands on neutrophils or in a different manner to the same ligands. Indeed, Lawrence and Springer (27) reported that neutrophils attach similarly to $\mathrm{P}$ - and E-selectin under flow conditions, but form much stronger rolling adhesions on E-selectin than on P-selectin, as measured by lower velocities and greater resistance to detachment by increasing shear stress. A concern in interpreting these experiments is that the authors compared the rolling of neutrophils on E-selectin coated on plastic with an earlier study in which they studied the rolling of neutrophils on P-selectin incorporated into planar membranes (28).

In this study, we directly compared the attachment and rolling of neutrophils on P-selectin and E-selectin under flow, with emphasis on the functions of L-selectin and PSGL-1. Each selectin was studied at a range of site densities when coated on plastic or expressed on the surface of Chinese hamster ovary (CHO) cells. In both formats, flowing neutrophils attached more efficiently and with greater adhesive strength to P-selectin than to E-selectin. Studies with mAbs suggested that PSGL-1 must function cooperatively with L-selectin to mediate optimal attachment of flowing neutrophils to E-selectin but not to Pselectin.

\section{Methods}

Materials. $O$-sialoglycoprotein endopeptidase (OSGE) from Pasturella hemolytica $(5 \mathrm{mg}$ glycophorin A cleaved $/ \mathrm{mg}$ protein $/ \mathrm{h}, \mathrm{EC} 3.4 .24 .93 \mathrm{~A}$ ) was obtained from Cedarlane Laboratories Ltd. (Hornby, Ontario, Canada). $N$-formyl-Met-Leu-Phe (FMLP), cytochalasin D, 2-deoxy-D-glucose, and Histopaque ${ }^{\circledR} 1077$ were purchased from Sigma Chemical Co. (St. Louis, MO). FITC goat anti-mouse IgG/IgM F $\left(\mathrm{ab}^{\prime}\right)_{2}$ was purchased from Caltag Laboratories (San Francisco, CA).

Proteins. Human platelet P-selectin was purified as described previously (29). Recombinant soluble forms of P-selectin (sPS) and Eselectin (sES) were produced and characterized as described previously
$(11,30)$. sES was a generous gift from Dr. David E. Lyons (Amgen, Inc., Thousand Oaks, CA).

Antibodies. The anti-human P-selectin mAbs S12, W40, G1, and G3 (all $\mathrm{IgG}_{1}-\kappa$ ) were prepared and characterized as described previously (31-33). G1 and G3, but not S12 and W40, block binding of P-selectin to leukocytes $(32,34)$. G1, but not S12, blocks binding of P-selectin to PSGL-1 (11). The anti-human E-selectin mAbs CL2 and CL37 $\left(\mathrm{IgG}_{1}-\kappa\right)$ were kindly provided by $\mathrm{C}$. Wayne Smith (Baylor College of Medicine, Houston, TX) (35). CL2, but not CL37, blocks binding of leukocytes to E-selectin. The anti-human L-selectin mAb DREG-56 $\left(\mathrm{IgG}_{1}\right)$ was a gift from Takashi Kei Kishimoto (Boehringer Ingelheim Pharmaceuticals, Inc., Ridgefield, CT) (36). The anti-human CD18 mAb IB4 $\left(\operatorname{IgG}_{2 A^{-}} \kappa\right)$ was a gift from Samuel D. Wright (The Rockefeller University, New York) (37). FITC-Leu 8 (anti-L-selectin) and PELeu 15 (anti-CD1 1b) were purchased from Becton Dickinson Immunocytometry Systems (San Jose, CA). The anti-human PSGL-1 mAbs PL1, PL2, and PL3 were prepared as described previously (25). PL1, but not PL2, abolishes binding of ${ }^{125}$ I-PSGL-1 to P-selectin, binding of fluid-phase P-selectin to leukocytes, and adhesion of neutrophils to Pselectin CHO cells under both static and flow conditions. PL3 competes with PL2 for binding to purified PSGL-1 and does not block binding of PSGL-1 to P-selectin. The LPS levels in purified PL1 and PL2 were quantified with a Limulus amebocyte lysate kit (QCL-1000 kit; BioWhittaker, Inc., Walkersville, MD) using endoxin from Escherichia coli strain 0111:B4 as standard. At a concentration of $15 \mu \mathrm{g} / \mathrm{ml}$, PL1 and PL2 each contained $<1 \mathrm{pg} / \mathrm{ml}(0.03 \mathrm{EU} / \mathrm{ml})$ of LPS.

Monoclonal antibody production. mAbs to human E-selectin were produced using previously cited methods (38), using SES as the immunogen. Two mAbs, designated ES1 and ES2 (both $\operatorname{IgG}_{1-\kappa}$ ), were purified and further characterized. Both $\mathrm{mAbs}$ bound specifically to E-selectin CHO cells but not P-selectin CHO cells, and both recognized a single 110-kD protein in extracts of E-selectin $\mathrm{CHO}$ cells, but not $\mathrm{P}$ selectin $\mathrm{CHO}$ cells, as assessed by Western blotting under nonreducing conditions. ES1, but not ES2, abolished binding of neutrophils to Eselectin CHO cells, but not P-selectin CHO cells, under both static and flow conditions. Neither mAb bound to leukocytes, indicating no crossreaction with $\mathrm{L}$-selectin.

Preparation of E-selectin and P-selectin substrates. Selectins diluted in HBSS were incubated at $4^{\circ} \mathrm{C}$ overnight in 12- or $35-\mathrm{mm}$ tissue culture plates (Corning Inc., Corning, NY). The plates were washed twice with HBSS and then blocked at $22^{\circ} \mathrm{C}$ for $2 \mathrm{~h}$ with $\mathrm{HBSS} / 1 \% \mathrm{HSA}$.

cDNA constructs and transfections. $\mathrm{CHO}$ cells were transfected with P-selectin or E-selectin cDNA in the vector PBK-EF using Lipofectamine $^{\mathrm{TM}}$ (Gibco BRL, Gaithersburg, MD) (25). Several dozen stably transfected clones expressing various densities of each selectin at confluence were selected as described previously (25). A portion of the cells from each clone was frozen. In addition, 10 clones expressing Pselectin and 10 clones expressing E-selectin at various matched densities were continuously maintained for use in adhesion experiments.

Site density determinations. Site densities of P- and E-selectin on plastic and on confluent transfected $\mathrm{CHO}$ cells were determined using radiolabeled mAbs directed at nonoverlapping epitopes on P-selectin (G1, G3, S12, W40) or E-selectin (CL2, CL37) as described previously (25). In calculating the site densities on CHO cells, the surface area of the cell monolayer was assumed to be identical to that of the culture dish; the site densities may be lower if the surface area of the monolayer exceeded that of the dish. Site densities were identical when measured in 48-well plates or in 35-mm dishes. For each cell adhesion experiment with protein-coated plastic, selectins were coated at several different concentrations in both 48 -well plates and $35-\mathrm{mm}$ dishes. Site density measurements were performed on the 48-well plates, and the measurements were used to select $35-\mathrm{mm}$ plates with matched densities of P-selectin and E-selectin for the experiment. For each cell adhesion experiment with transfected $\mathrm{CHO}$ cells, the 20 stably transfected cell lines were individually plated in both 48 -well plates and $35-\mathrm{mm}$ dishes. Site density measurements were performed in the 48-well plates when the cells reached confluence; these measurements were performed on the day before the experiment or on the day of the experiment. The 
measurements were used to select $35-\mathrm{mm}$ plates with confluent $\mathrm{CHO}$ cell monolayers expressing matched densities of P-selectin and E-selectin for the experiment.

Cell isolation. Neutrophils were isolated from healthy human donors as described previously (39). HL-60 cells were maintained in RPMI 1640/20\% FCS supplemented with $4 \mathrm{mM}$ L-glutamine, $100 \mathrm{IU} / \mathrm{ml}$ penicillin, and $100 \mu \mathrm{g} / \mathrm{ml}$ streptomycin. HL-60 cells were treated with OSGE $\left(10 \mu \mathrm{l} / 5 \times 10^{6}\right.$ cells, $1 \mathrm{~h}, 37^{\circ} \mathrm{C}$ ) in $\mathrm{Ca}^{2+} / \mathrm{Mg}^{2+}$-free HBSS supplemented with $1 \% \mathrm{HSA}, 1 \mathrm{mM} \mathrm{CaCl}$, and $0.02 \% \mathrm{NaN}_{3}$.

Adhesion of neutrophils to $P$ - and E-selectin under flow conditions. Fluid shear stresses present in the microvasculature were simulated in a parallel-plate flow chamber as described previously $(23,25)$. Neutrophils $\left(10^{6} / \mathrm{ml}\right)$ in HBSS $/ 0.5 \%$ HSA were perfused through the chamber at the desired wall shear stress. Neutrophil rolling was allowed to equilibrate for $4 \mathrm{~min}$ on $\mathrm{CHO}$ cells and for $8 \mathrm{~min}$ on selectin-coated plastic before data acquisition. Experiments comparing control and test neutrophils were performed in parallel chambers on the same culture dish. Neutrophil interactions were visualized with a $\times 40$ objective (field of view of $0.032 \mathrm{~mm}^{2}$ ) using phase-contrast video microscopy. Interactions were quantified using a computer imaging system (Sun Microsystem, Mountain View, CA; Inovision, Durham, NC). The number of adherent or rolling neutrophils was measured by digitizing image frames and determining the number of cells that were firmly adherent or rolling as described previously (23). Detachment of neutrophils was determined by allowing neutrophils to adhere to the surface under static conditions, then initiating flow at a wall shear stress of $1 \mathrm{dyn} / \mathrm{cm}^{2}$. The wall shear stress was increased incrementally every $30 \mathrm{~s}$ and the number of neutrophils remaining adherent was determined. All experiments were performed at $22^{\circ} \mathrm{C}$ unless indicated otherwise. In certain experiments, cells were preincubated for $10 \mathrm{~min}$ with $5-10 \mu \mathrm{g} / \mathrm{ml}$ of anti-PSGL-1, anti$\mathrm{CD} 18$, or anti-L-selectin mAb and rolling was assayed in the continuous presence of the mAb. In some experiments, cells $\left(10^{6} / \mathrm{ml}\right.$ in HBSS/ $0.5 \%$ HSA) were treated with $2 \mu \mathrm{M}$ cytochalasin D or DMSO diluent for $10 \mathrm{~min}$ at $37^{\circ} \mathrm{C}$, followed by sham or FMLP treatment $(0.1 \mu \mathrm{M}$, $\left.10-15 \mathrm{~min}, 37^{\circ} \mathrm{C}\right)$. In other experiments, cells $\left(10^{6} / \mathrm{ml}\right.$ in $\mathrm{HBSS} / 0.5 \%$ HSA) were incubated with $50 \mathrm{mM}$ 2-deoxyglucose and $0.06 \% \mathrm{NaN}_{3}$ for $60 \mathrm{~min}$ at $22^{\circ} \mathrm{C}$ in $\mathrm{HBSS} / 0.5 \% \mathrm{HSA}(25)$. All inhibitors remained present during the adhesion assays. In additional studies, neutrophils were fixed with $1 \%$ paraformaldehyde in HBSS for 20 min at $4^{\circ} \mathrm{C}$, washed twice in HBSS, and resuspended in HBSS/0.5\% HSA.

Adhesion of neutrophils to $P$ - and E-selectin under static conditions. Transfected CHO cells were grown to confluence in 24-well dishes. The monolayers were washed once with HBSS and then neutrophils (250 $\mu 1,5 \times 10^{5}$ cells) in HBSS $/ 0.5 \%$ HSA were added. After $15 \mathrm{~min}$ at $37^{\circ} \mathrm{C}$, nonadherent neutrophils were removed by gentle washing and the number of adherent neutrophils was quantitated using a myeloperoxidase assay as described previously (32).

Flow cytometry. For direct immunofluorescence staining, $10^{6}$ cells were stained with $20 \mu \mathrm{l}$ of FITC-Leu8 or PE-Leu15. For indirect immunofluorescence, $10^{6}$ cells were incubated with $50 \mu \mathrm{l}$ of mAb at a concentration of $10 \mu \mathrm{g} / \mathrm{ml}$. Bound antibody was detected with FITC-conjugated goat anti-mouse IgG/IgM. Each incubation was for $30 \mathrm{~min}$ at $4^{\circ} \mathrm{C}$ in HBSS/HSA/Ca, between which the cells were washed with HBSS/ $\mathrm{HSA} / \mathrm{Ca}$. After the last wash, the cells were fixed with $1 \%$ paraformaldehyde and analyzed using a Becton-Dickinson FACScan ${ }^{\circledR}$ flow cytometer. Binding of platelet-derived P-selectin to neutrophils or HL-60 cells was measured by flow cytometry as described previously $(13,25)$.

\section{Results}

Neutrophils attach more efficiently to P-selectin than to Eselectin under flow conditions. We used a parallel-plate, dualchamber flow system to directly compare the attachment and rolling of neutrophils on P-selectin and E-selectin under physiological shear stresses. Comparable site densities of P-selectin and E-selectin were coated on plastic or expressed on the surface of transfected CHO cells. Site densities were measured before
Table I. Measurement of Selectin Site Densities*

\begin{tabular}{lcccc}
\hline & \multicolumn{4}{c}{ Site density $\left(\mathrm{sites} / \mu \mathrm{m}^{2}\right)$} \\
\cline { 2 - 5 } \multicolumn{1}{c}{ Surface } & G1 & CL2 & S12 & CL37 \\
\hline P-selectin CHO & $172 \pm 3$ & - & $180 \pm 18$ & - \\
E-selectin CHO & - & $98 \pm 1$ & - & $63 \pm 6$ \\
sPS & $187 \pm 11$ & - & $2874 \pm 256$ & - \\
sES & - & $248 \pm 20$ & - & $106 \pm 6$
\end{tabular}

* Site densities were determined for P- and E-selectin expressed on CHO cells and for sPS and sES coated on plastic. Measurements were made using either blocking mAbs (G1 and CL2) or nonblocking mAbs (S12 and CL37) to P- and E-selectin. The data represent the mean \pm range of duplicate determinations and are representative of at least four independent experiments in which site densities were measured with both blocking and nonblocking mAbs. Similar results were obtained when the anti-P-selectin blocking mAb G3 was used instead of $\mathrm{G} 1$ and when the nonblocking anti-P-selectin mAb W40 was used instead of S12. Immobilized platelet-derived P-selectin also displayed many more epitopes for nonblocking mAbs than for blocking mAbs.

each experiment to ensure that matched densities of P-selectin and E-selectin were used ( see Methods). In preliminary studies, we compared site densities measured with either inhibitory or noninhibitory mAbs to P-selectin and E-selectin (Table I). On CHO cells, similar site densities were measured using either inhibitory or noninhibitory $\mathrm{mAbs}$ to P-selectin or E-selectin. On plastic, similar site densities were also measured with inhibitory or noninhibitory mAbs to E-selectin. However, P-selectin coated on plastic displayed many more epitopes for noninhibitory mAbs than for inhibitory mAbs, presumably because the latter epitopes on many P-selectin molecules are obscured by the interaction with the plastic. In all cell adhesion experiments, site densities were measured with inhibitory mAbs, since these epitopes are likely to reflect regions of the selectins that directly participate in neutrophil recognition.

In both plastic and $\mathrm{CHO}$ cell formats, neutrophils attached to and rolled on P-selectin and E-selectin at a range of shear stresses characteristic of postcapillary venules (Fig. 1). More neutrophils attached to a selectin coated on plastic than to the same selectin expressed on $\mathrm{CHO}$ cells at matched densities. Attachment was always followed by rolling. Attachment of neutrophils was completely inhibited by buffer containing EGTA or by buffer containing an inhibitory $\mathrm{mAb}$, but not a noninhibitory $\mathrm{mAb}$, to the appropriate selectin (data not shown). Thus, attachment and rolling of neutrophils were dependent on the selectin, whether presented on plastic or on $\mathrm{CHO}$ cells.

Neutrophils attached much more efficiently to P-selectin than to E-selectin at comparable site densities (Fig. 1). At a wall shear stress of $2 \mathrm{dyn} / \mathrm{cm}^{2}$, neutrophils attached avidly to P-selectin at densities as low as $10-25$ sites $/ \mu \mathrm{m}^{2}$, and the number of attached cells reached maximum at relatively low densities $\left(\approx 50\right.$ sites $\left./ \mu \mathrm{m}^{2}\right)$. In contrast, higher densities of E-selectin were required to support neutrophil attachment (Fig. 1, $A$ and $B$ ). Neutrophil attachment reached a maximum at an E-selectin density of $\approx 300$ sites $/ \mu \mathrm{m}^{2}$ (data not shown). Neutrophils attached more efficiently to P-selectin than to E-selectin over a range of shear stresses (Fig. 1, $C$ and $D$ ). At comparable selectin densities, more neutrophils attached to P-selectin than to Eselectin on both protein-coated surfaces and on transfected $\mathrm{CHO}$ 

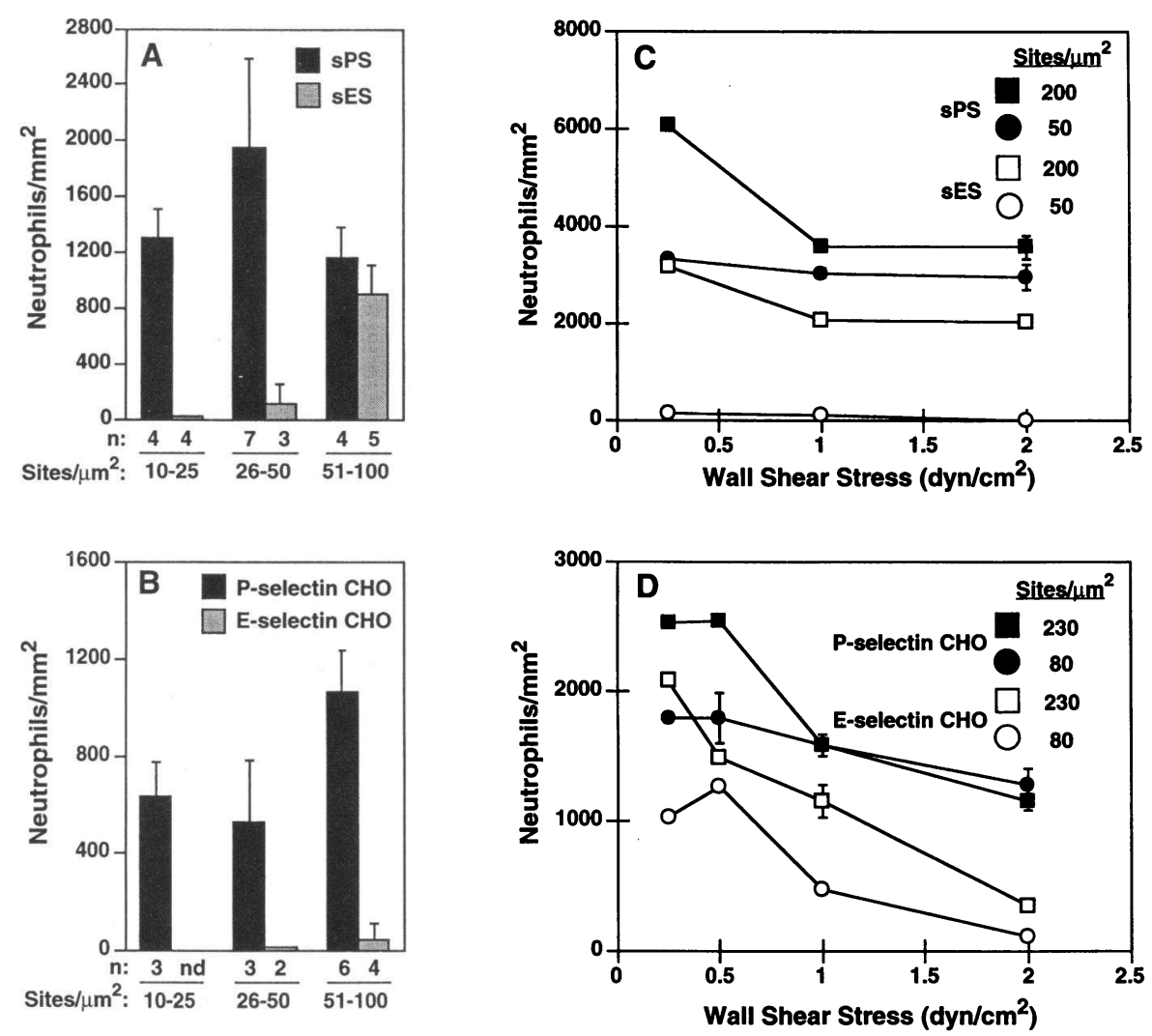

Figure 1. Neutrophils attach more efficiently to P-selectin than to E-selectin under flow conditions. sPS or SES was immobilized at various site densities on $35-\mathrm{mm}$ tissue culture dishes ( $A$ and $C$ ), and $\mathrm{CHO}$ cells expressing $\mathrm{P}$ - or E-selectin at various site densities were grown to confluence on 35-mm tissue culture dishes $(B$ and $D)$. The dishes were inserted into a parallel-plate flow chamber and the chambers were perfused with neutrophils $\left(10^{6} / \mathrm{ml}\right)$ in HBSS $/ 0.5 \%$ HSA at $2 \mathrm{dyn} / \mathrm{cm}^{2}$ $(A$ and $B)$ or at the indicated wall shear stress for either $8 \mathrm{~min}(A$ and $C)$ or $4 \mathrm{~min}(B$ and $D$ ) before data acquisition. The number of rolling neutrophils was quantitated. The data in $A$ and $B$ represent the mean \pm SD of the number of rolling neutrophils in two randomly selected $\times 40$ fields determined in the indicated number of independent experiments. The data points in $C$ and $D$ represent the mean \pm range of the number of rolling neutrophils in two randomly selected $\times 40$ fields and are representative of two independent experiments. The error bars for some data points are not visible because the error bars were smaller than the size of the symbols. $n d$, not done. cells. At higher site densities, however, the superior attachment to P-selectin was evident only at shear stresses $>2 \mathrm{dyn} / \mathrm{cm}^{2}$.

Neutrophils roll at lower velocities on P-selectin than on E-selectin. We examined the rolling velocities of neutrophils that attached under shear forces as a measure of their adhesive strengths to P- or E-selectin. The velocities of 50 randomly selected neutrophils rolling on P- or E-selectin at comparable site densities were determined. At a selectin density of 200 sites $/ \mu \mathrm{m}^{2}$ and a wall shear stress of $2 \mathrm{dyn} / \mathrm{cm}^{2}$, virtually all neutrophils rolled very slowly on P-selectin coated on plastic (Fig. $2 A$ ). In contrast, neutrophils rolled with heterogeneous velocities on E-selectin, and most cells rolled at substantially higher velocities than on P-selectin. On transfected $\mathrm{CHO}$ cells expressing $230 \mathrm{sites} / \mu \mathrm{m}^{2}$ of each selectin, the velocities of neutrophils rolling on P-selectin were somewhat more heterogeneous than on P-selectin coated on plastic, but the neutrophils still rolled significantly slower on P-selectin than on E-selectin (Fig. $2 B$ ). In both formats, rolling velocities decreased as the site densities of $\mathrm{P}$ - and E-selectin were increased, but the average velocity on P-selectin was always lower than on E-selectin at a given site density (data not shown). For both P- and Eselectin, there was less variation in the rolling velocities of individual neutrophils on protein-coated plastic than on transfected CHO cells.

Shear stress readily detaches neutrophils that adhered statically to $\mathrm{P}$ - or E-selectin expressed on $\mathrm{CHO}$ cells but not coated on plastic. We allowed neutrophils to settle on selectin surfaces in the absence of flow, then subjected the adherent cells to progressively increasing wall shear stresses. Upon initiation of flow, the neutrophils began to roll. The percentage of rolling cells that remained adherent as a function of wall shear stress was determined as an alternative measure of adhesive strength.
Resistance to detachment increased as a function of site density for both selectins, and neutrophils tended to be more resistant to detachment when adherent to P-selectin than to E-selectin at comparable site densities (data not shown). However, the most striking finding was that neutrophils adherent to either selectin coated on plastic were resistant to detachment even at shear forces $>30 \mathrm{dyn} / \mathrm{cm}^{2}$ (Fig. 3 ). In contrast, neutrophils adherent
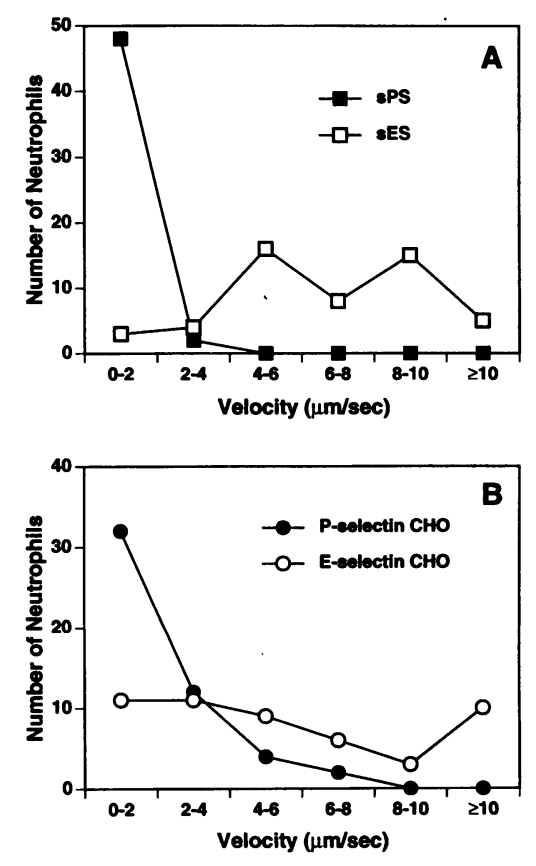

Figure 2. Neutrophils roll at lower velocities on P-selectin than on E-selectin. Neutrophil rolling velocities were determined at $2 \mathrm{dyn} / \mathrm{cm}^{2}$ on (A) SPS or SES immobilized on plastic at $\approx 200$ sites/ $\mu \mathrm{m}^{2}$ or $(B) \mathrm{CHO}$ cells expressing P-selectin or E-selectin at $\approx 230$ sites $/ \mu \mathrm{m}^{2}$. The data represent the velocity proneutrophils and are representative of three independent experiments. files of 50 individual 


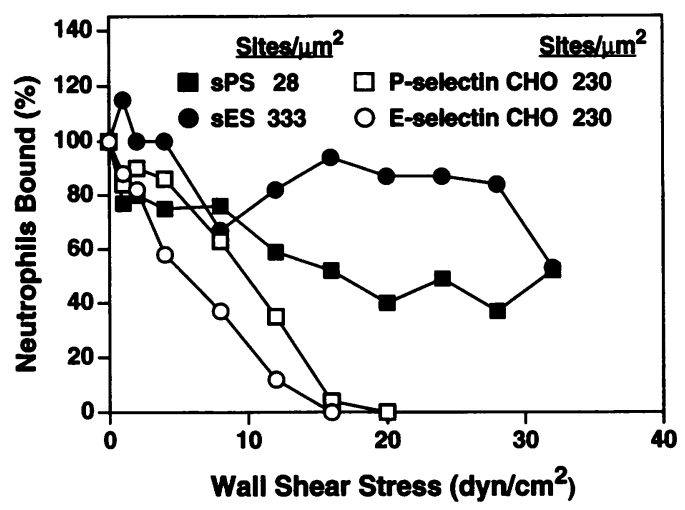

Figure 3. Neutrophils adherent to P- and E-selectin coated on plastic are more resistant to detachment by shear forces than neutrophils adherent to P- and E-selectin CHO cells. sPS or sES was immobilized at the indicated site density on 35-mm tissue culture dishes, and $\mathrm{CHO}$ cells expressing $\mathrm{P}$ - or E-selectin at the indicated site density were grown to confluence on $35-\mathrm{mm}$ tissue culture dishes. Neutrophils $\left(10^{6} / \mathrm{ml}\right)$ in HBSS $/ 0.5 \%$ HSA were allowed to bind to the selectin surfaces for 5 min under static conditions. Flow was initiated at $0.25 \mathrm{dyn} / \mathrm{cm}^{2}$ for 30 $s$ to remove loosely adherent cells and the number of adherent cells remaining was taken to be $100 \%$ bound. Similar numbers of cells bound to immobilized sPS or sES or to P- or E-selectin CHO cells. Shear was increased every $30 \mathrm{~s}$ and the number of neutrophils bound to the selectin was quantified and the percent remaining was determined. The data are representative of five independent experiments.

to $\mathrm{P}$ - or E-selectin expressed on $\mathrm{CHO}$ cells detached at much lower shear stresses, with complete detachment at shear stresses of $\sim 15 \mathrm{dyn} / \mathrm{cm}^{2}$ at all site densities examined (Fig. 3 and data not shown). The rolling velocities of neutrophils on selectincoated plastic reached a plateau despite further increases in shear stress, whereas the velocities of neutrophils on selectintransfected $\mathrm{CHO}$ cells continued to increase until they detached from the monolayer (data not shown).

The remarkable resistance to detachment of neutrophils adherent to selectin-coated plastic resembled that previously observed for $\beta 2$ integrin-dependent adhesion of activated neutrophils (28). However, the adherent cells remained round and refractile to light, suggesting that they were not activated. Furthermore, conditions that suppress $\beta 2$ integrin function did not diminish the resistance to detachment of neutrophils adherent to P- or E-selectin coated on plastic. These conditions included fixation of the neutrophils, chilling to $4^{\circ} \mathrm{C}$, use of $\mathrm{Mg}^{2+}$-free buffer, treatment of neutrophils with the metabolic inhibitors $\mathrm{NaN}_{3}$ and 2-deoxyglucose, or infusion of an inhibitory mAb to $\beta 2$ integrins (data not shown). Finally, infusion of EGTA or of inhibitory mAbs to the appropriate selectin rapidly detached adherent cells from selectin-coated plastic under shear stresses, indicating that the cells adhered by mechanisms requiring selectins rather than integrins (data not shown). The resistance of neutrophils to detachment from immobilized selectins may reflect an adhesive contribution from the plastic. We performed all subsequent experiments on selectin-expressing $\mathrm{CHO}$ cells, since they seemed more likely to represent physiologically relevant surfaces.

Purified PSGL-1 interacts differently with E-selectin than with P-selectin. We previously developed two anti-PSGL-1 IgG mAbs, termed PL1 and PL2. PL1, but not PL2, completely blocks binding of purified PSGL-1 to P-selectin and abolishes

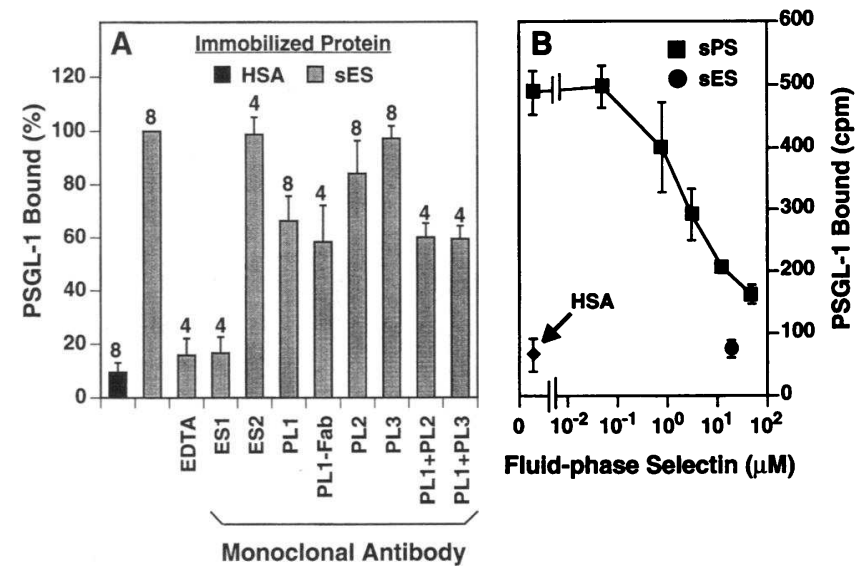

Figure 4. Effects of mAbs and fluid-phase selectins on binding of PSGL1 to immobilized E-selectin. A fixed concentration of ${ }^{125}$ I-PSGL-1 was incubated for $1 \mathrm{~h}$ in microtiter plates coated with HSA or with SES (50 $\mu \mathrm{l}, 25 \mu \mathrm{g} / \mathrm{ml}$ ) in the presence of (A) buffer, $5 \mathrm{mM}$ EDTA, $10 \mu \mathrm{g} / \mathrm{ml}$ of anti-E-selectin mAb (ES1 or ES2), $10 \mu \mathrm{g} / \mathrm{ml}$ of anti-PSGL-1 mAb (PL1, PL1 Fab fragments, PL2, or PL3), or $(B)$ increasing concentrations of either fluid-phase sPS or sES. The data in $A$ represent the mean $\pm \mathrm{SD}$ of the indicated number of independent experiments, each performed in quadruplicate. The data in $B$ represent the mean \pm SD of quadruplicate wells and are representative of two independent experiments.

adhesion of neutrophils to P-selectin under both static and shear conditions (25). E-selectin binds near the P-selectin-binding site on PSGL-1, because fluid-phase E-selectin inhibits binding of ${ }^{125} \mathrm{I}$-PSGL-1 to immobilized P-selectin (11). However, the IC50 is $\sim 50$-fold higher for fluid-phase E-selectin than for Pselectin, suggesting that E-selectin binds with lower equilibrium affinity to this site (11). To determine whether PSGL-1 participates in the adhesion of neutrophils to E-selectin, we first examined whether the anti-PSGL-1 mAbs affected binding of purified PSGL-1 to E-selectin. ${ }^{125} \mathrm{I}$-PSGL-1 bound in a $\mathrm{Ca}^{2+}$-dependent manner to immobilized E-selectin (Fig. $4 A$ ). The binding was blocked by ES1, an inhibitory mAb to E-selectin, but not by ES2, a noninhibitory mAb to E-selectin. PL1 only partially inhibited binding of PSGL-1 to E-selectin, although the inhibition was consistent. In multiple experiments, PL1 IgG or Fab fragments reduced binding by $\sim 40 \%$ (Fig. $4 A$ ). PL2 and PL3, two anti-PSGL-1 mAbs that compete for the same binding site, did not inhibit binding to E-selectin and did not further block binding when used in combination with PL1 (Fig. $4 \mathrm{~A}$ ). Fluidphase E-selectin $(20 \mu \mathrm{M})$ completely inhibited binding of ${ }^{125} \mathrm{I}$ PSGL-1 to immobilized E-selectin (Fig. $4 \mathrm{~B}$ ). Fluid-phase Pselectin also inhibited binding in a concentration-dependent manner, although inhibition was still incomplete at the highest concentration tested $(50 \mu \mathrm{M})$. These data, coupled with previous results on the binding of PSGL-1 to immobilized P-selectin $(11,25)$, indicate that PSGL-1 does not interact identically with P-selectin and E-selectin. The results suggest that both Pselectin and E-selectin bind to a site that is near the epitope for PL1, although E-selectin binds with lower affinity than P-selectin to this site (11). A less likely possibility is that PL1 indirectly alters the conformation of the recognition site for $\mathrm{P}$ - and E-selectin. PL1 completely inhibits binding of PSGL-1 to Pselectin, suggesting that it identifies the dominant recognition site for P-selectin (25). In contrast, PL1 only partially inhibits 

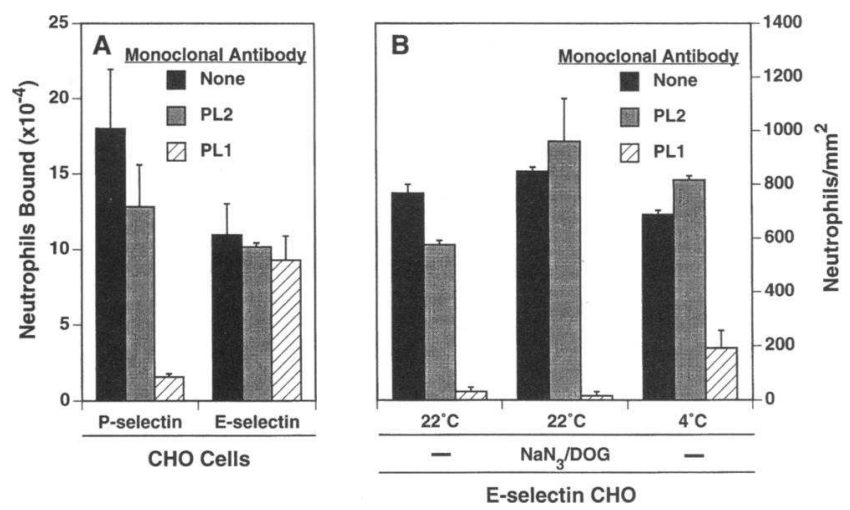

Figure 5. PSGL-1 is required for optimal attachment of neutrophils to E-selectin under flow conditions but is not essential for attachment under static conditions. $\mathrm{CHO}$ cells expressing P- or E-selectin at $\approx 200$ sites/ $\mu \mathrm{m}^{2}$ were grown to confluence on $35-\mathrm{mm}$ tissue culture dishes. Neutrophils $\left(10^{6} / \mathrm{ml}\right)$ in HBSS $/ 0.5 \%$ HSA were preincubated with PL1, PL2 ( $5 \mu \mathrm{g} / \mathrm{ml}$ ), or buffer for $10 \mathrm{~min}$. Adhesion of neutrophils was measured under $(A)$ static conditions or $(B)$ flow conditions $\left(1.5 \mathrm{dyn} / \mathrm{cm}^{2}\right)$. In certain experiments, neutrophils $\left(10^{6} / \mathrm{ml}\right)$ were chilled to $4^{\circ} \mathrm{C}$ or pretreated with a mixture of $50 \mathrm{mM}$ 2-deoxyglucose $(D O G)$ and $0.06 \%$ $\mathrm{NaN}_{3}$ in HBSS $/ 0.5 \% \mathrm{HSA}$ for $60 \mathrm{~min}$ at $22^{\circ} \mathrm{C}$. The data represent the mean \pm range of the number of rolling neutrophils in two randomly selected $\times 40$ fields and are representative of at least three independent experiments.

binding of PSGL-1 to E-selectin, suggesting that PSGL-1 has one or more additional recognition sites for E-selectin. Fluidphase P-selectin binds weakly to one or more of these sites, as reflected by its ability to partially inhibit binding of ${ }^{125} \mathrm{I}$-PSGL1 to immobilized E-selectin. However, these sites do not contribute measurably to binding of ${ }^{125}$ I-PSGL-1 to immobilized P-selectin in the presence of PL1 (25).

PSGL-1 is required for optimal attachment of neutrophils to E-selectin under flow conditions but is not essential for attachment under static conditions. Although PL1 only partially inhibited binding of purified PSGL-1 to E-selectin, we wondered whether the recognition site for E-selectin identified by the antibody might contribute to the adhesion of neutrophils to E-selectin. Therefore, we examined the effects of PL1 and PL2 on neutrophil attachment to E-selectin CHO cells under both static and shear conditions (Fig. 5). Under static conditions, neither PL1 nor PL2 inhibited adhesion of neutrophils to Eselectin CHO cells (Fig. 5 A). In contrast, PL1, but not PL2, significantly inhibited attachment of neutrophils on the same $E$ selectin CHO cells at a shear stress of $1.5 \mathrm{dyn} / \mathrm{cm}^{2}$ (Fig. $5 \mathrm{~B}$ ). PL1 also inhibited attachment of neutrophils that were rendered metabolically inactive by chilling to $4^{\circ} \mathrm{C}$ or treatment with $\mathrm{NaN}_{3}$ and 2-deoxyglucose (Fig. $5 \mathrm{~B}$ ). Monovalent Fab fragments of PL1 inhibited attachment, indicating that the effects of PL1 were not due to redistribution of PSGL-1 by bivalent IgG (data not shown). Finally, PL1 inhibited attachment and rolling of fixed neutrophils on E-selectin, suggesting that the mAb did not inhibit rolling indirectly through cell signaling (data not shown).

PL1 always abolishes rolling of neutrophils on P-selectin (25). In contrast, PL1 did not completely inhibit rolling of neutrophils on E-selectin. In multiple experiments with $\mathrm{CHO}$ cells expressing E-selectin at a variety of site densities, PL1 blocked rolling of neutrophils on E-selectin $\mathrm{CHO}$ cells by

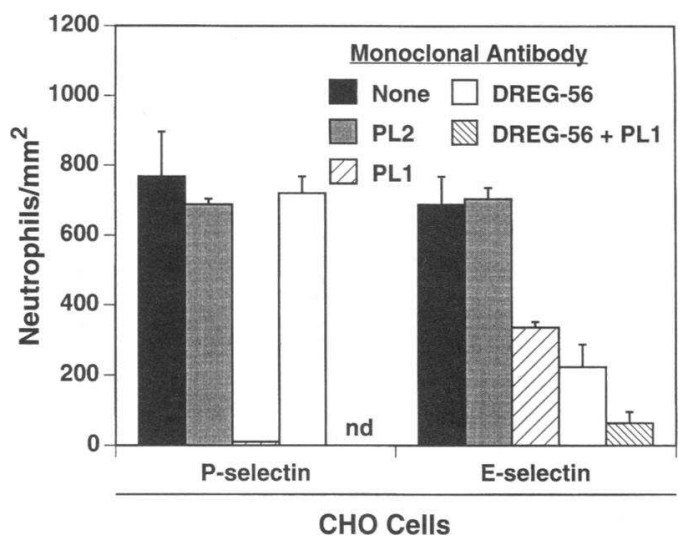

Figure 6. Effect of anti-L-selectin mAb on attachment of neutrophils to $\mathrm{P}$ - and E-selectin under flow conditions. $\mathrm{CHO}$ cells expressing Pselectin or E-selectin at $\approx 200$ sites $/ \mu \mathrm{m}^{2}$ were grown to confluence on 35-mm tissue culture dishes and inserted into a parallel-plate flow chamber. Neutrophils were incubated with PL1, PL2, and/or DREG-56 (5 $\mu \mathrm{g} / \mathrm{ml})$, or buffer for $10 \mathrm{~min}$. The cells $\left(10^{6} / \mathrm{ml}\right)$ were perfused through the flow chamber at $1.5 \mathrm{dyn} / \mathrm{cm}^{2}$ for $4 \mathrm{~min}$ before data acquisition and the number of rolling neutrophils was quantitated. The data represent the mean \pm range of the number of rolling neutrophils in two randomly selected $\times 40$ fields and are representative of at least four independent experiments. $n d$, not done.

$73.8 \pm 19.5 \%($ mean $\pm \mathrm{SD}, n=22)$. The variable degree of inhibition did not correlate with the density of E-selectin on the CHO cells, and higher concentrations of PL1 did not further inhibit rolling. In all experiments, PL1 substantially inhibited attachment of neutrophils to E-selectin under shear stresses, but had no effect on adhesion under static conditions. Taken together, these data suggest that bonds between E-selectin and the site on PSGL-1 that overlaps the PL1 epitope play an important role in attachment of neutrophils to E-selectin under shear forces. However, other ligands for E-selectin, and/or other recognition sites for E-selectin on PSGL-1, also contribute to attachment under flow. These alternative ligands are particularly important as mediators of adhesion in the absence of shear stress.

Effects of anti-L-selectin $m A b$ and cell activation on attachment of neutrophils to P-selectin and E-selectin under flow conditions. Previous studies have suggested that neutrophils require $\mathrm{L}$-selectin to attach to E-selectin under shear forces, but not under static conditions (22). To determine whether L-selectin functions cooperatively with PSGL-1 in mediating attachment of flowing neutrophils to E- or P-selectin, we preincubated the cells with PL1, PL2, or DREG-56, a mAb to Lselectin that partially inhibits rolling of neutrophils on P- or Eselectin in some experimental systems (22-24). As demonstrated previously (25), PL1, but not PL2, abolished rolling of neutrophils on P-selectin (Fig. 6). Under these conditions, DREG-56 did not affect rolling on P-selectin. In contrast, PL1 and DREG-56 each partially inhibited rolling of the same neutrophils on E-selectin, and a combination of both mAbs further inhibited rolling (Fig. 6). When used alone, DREG-56 inhibited neutrophil rolling on E-selectin by $70.1 \pm 12.9 \%$ (mean $\pm \mathrm{SD}, n$ $=11$ ). Flow cytometric analysis indicated that the antibodytreated cells did not shed L-selectin or increase surface expression of CD11b, suggesting that they were not activated (data not shown). Furthermore, the cells remained round and refractile to 


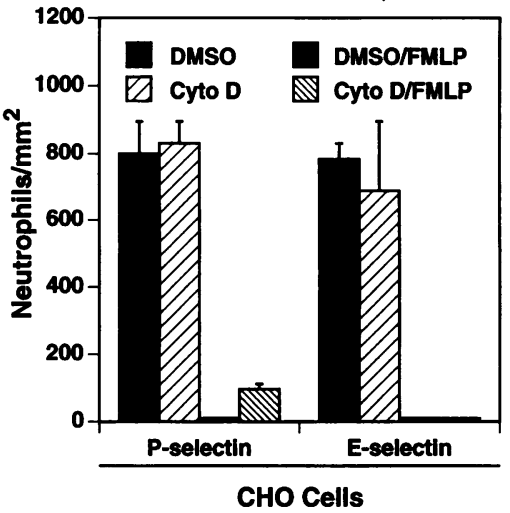

Figure 7. Effect of cell activation on attachment of neutrophils to $\mathrm{P}$ - or $\mathrm{E}$ selectin under flow. $\mathrm{CHO}$ cells expressing P- or Eselectin at $\approx 200$ sites/ $\mu \mathrm{m}^{2}$ were grown to confluence on $35-\mathrm{mm}$ tissue culture dishes and inserted into a parallelplate flow chamber. Neutrophils $\left(10^{6} / \mathrm{ml}\right)$ were pretreated with $2 \mu \mathrm{M}$ cytochalasin D (Cyto D) or diluent $(D M S O)$ in HBSS $/ 0.5 \%$ HSA for 10 min at $37^{\circ} \mathrm{C}$, followed by $0.1 \mu \mathrm{M}$ FMLP or buffer for $15 \mathrm{~min}$ at $37^{\circ} \mathrm{C}$. The cells $\left(10^{6} / \mathrm{ml}\right)$ were perfused through the flow chamber at $1.5 \mathrm{dyn} /$ $\mathrm{cm}^{2}$ for $4 \mathrm{~min}$ before data acquisition and the number of rolling neutrophils was quantitated. The data represent the mean \pm range of the number of rolling neutrophils in two randomly selected $\times 40$ fields and are representative of three independent experiments.

light. Similar results were observed when the neutrophils were pretreated with the metabolic inhibitors, $\mathrm{NaN}_{3}$ and 2-deoxyglucose, or when the neutrophils were fixed before analysis (data not shown). These results suggest that L-selectin does not significantly contribute to neutrophil attachment to P-selectin under these conditions. However, L-selectin functions cooperatively with PSGL-1 to mediate attachment of flowing neutrophils to E-selectin.

We next asked whether neutrophils that shed L-selectin after activation could attach to P- and E-selectin under flow. Activated cells develop asymmetric shapes that may interfere with attachment under shear forces. Therefore, some cells were treated with cytochalasin $\mathrm{D}$, an inhibitor of actin polymerization, to maintain their round shapes. Because the effects of cytochalasin $\mathrm{D}$ are rapidly reversible, the agent was maintained in the cell suspensions for the duration of the experiments. Resting or FMLP-activated neutrophils, in the presence of cytochalasin D or control diluent, were perfused over P- or E-selectin $\mathrm{CHO}$ cells. Flow cytometry with $\mathrm{mAbs}$ to L-selectin revealed that FMLP induced shedding of $95 \%$ of the L-selectin from the cell surface, in the presence or absence of cytochalasin D. However, the binding of PL1 and PL2 to activated neutrophils was unaltered, indicating that PSGL-1 remained on the cell surface (data not shown). Furthermore, flow cytometry indicated that activated neutrophils retained functional PSGL-1dependent binding sites for platelet-derived P-selectin (data not shown). Treatment of resting neutrophils with cytochalasin D did not affect attachment to P- or E-selectin, indicating that most actin filaments are not required for attachment under flow (Fig. 7 and reference 25). In contrast, neutrophils activated in the presence or absence of cytochalasin D failed to attach to either selectin under shear conditions (Fig. 7). The activationinduced shedding of L-selectin coincided with the loss of cell attachment, consistent with a requirement for L-selectin for flowing neutrophils to attach optimally to P- and E-selectin. However, DREG-56, unlike cell activation, did not inhibit attachment to P-selectin (Fig. 6). Therefore, other activationinduced changes may also impair attachment of flowing neutrophils to selectins.
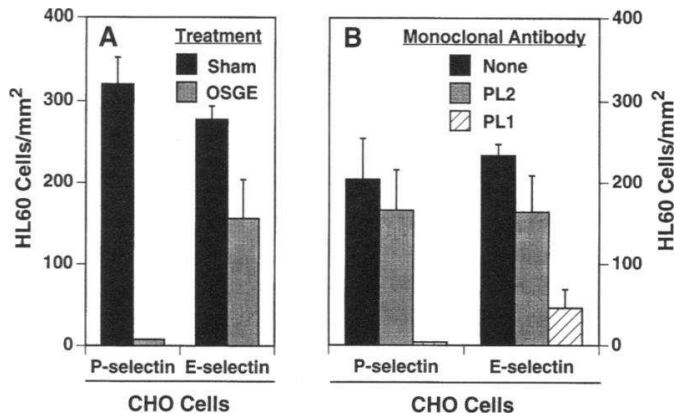

Figure 8. PSGL-1 is essential for attachment of HL-60 cells to P-selectin and is required for optimal attachment of HL-60 cells to E-selectin under flow conditions. CHO cells expressing P-selectin or E-selectin at $\approx 200$ sites $/ \mu \mathrm{m}^{2}$ were grown to confluence on $35-\mathrm{mm}$ tissue culture dishes and then inserted into a parallel-plate flow chamber. $(A) \mathrm{HL}-60$ cells were treated with OSGE or buffer. $(B)$ HL-60 cells were preincubated with PL1, PL2 $(10 \mu \mathrm{g} / \mathrm{ml})$, or buffer for $10 \mathrm{~min}$. The cells (2 $\times 10^{6} / \mathrm{ml}$ ) were perfused through the flow chamber at $1.5 \mathrm{dyn} / \mathrm{cm}^{2}$ for $4 \mathrm{~min}$ before data acquisition and the number of rolling HL-60 cells was determined. The data represent the mean \pm range of the number of rolling cells in four randomly selected $\times 20$ fields and are representative of two $(A)$ or five $(B)$ independent experiments.

PSGL-1 is essential for attachment of HL-60 cells to Pselectin and is required for optimal attachment of $H L-60$ cells to E-selectin under flow conditions. To further examine whether flowing myeloid cells could use PSGL-1 to attach to P- or Eselectin in the absence of L-selectin, we studied HL-60 cells. These cells lack L-selectin, but adhere to both E- and P-selectin under static conditions $(32,40)$. The enzyme OSGE, which cleaves sialomucin-like proteins (41), removes the PL1 epitope but not the PL2 epitope from PSGL-1 (25). Treatment of HL60 cells with OSGE eliminates static adhesion to P-selectin but not to E-selectin $(13,42)$. Fig. 8 demonstrates that HL-60 cells rolled on both P- and E-selectin CHO cells at a shear stress of $1.5 \mathrm{dyn} / \mathrm{cm}^{2}$, indicating that HL-60 cells do not require Lselectin to attach under shear forces. Rolling on P-selectin was completely blocked by treating the HL-60 cells with OSGE or by infusion of mAb PL1, but not PL2. These treatments also inhibited rolling on E-selectin (Fig. 8). In multiple experiments, PL1 inhibited rolling on E-selectin by $68.1 \pm 10.5 \%$ (mean $\pm S D$, $n=7)$. In parallel experiments, OSGE and PL1 abolished static adhesion of HL-60 cells to P-selectin, but had no effect on static adhesion of HL-60 cells to E-selectin (data not shown). Thus, flowing HL-60 cells use a region of PSGL-1 recognized by PL1 and altered by OSGE to attach to P- and E-selectin in the absence of L-selectin. Under static conditions, HL-60 cells require this portion of PSGL-1 to adhere to P-selectin but not to E-selectin.

\section{Discussion}

Our results indicate that $(a)$ flowing neutrophils attach with greater efficiency and roll at lower velocities on P-selectin than on E-selectin, $(b)$ purified PSGL-1 interacts differently with Pselectin than with E-selectin, and (c) PSGL-1 functions cooperatively with $\mathrm{L}$-selectin to mediate attachment of neutrophils to E-selectin under flow but not static conditions.

At physiological hydrodynamic parameters, more neutrophils attached to P-selectin than to E-selectin at matched site 
densities. Neutrophils that attached under shear forces also rolled at lower velocities on P-selectin than on E-selectin. These differences were observed with selectins coated on plastic as well as with selectins expressed on transfected $\mathrm{CHO}$ cells. The greater attachment to P-selectin indicates that neutrophils formed more initial bonds with P-selectin than with E-selectin. The slower rolling velocities on P-selectin indicate that, after attachment, neutrophils continued to form more bonds with Pselectin than E-selectin and/or that the bonds dissociated at a slower rate.

Lawrence and Springer (27) observed previously that neutrophils adherent to E-selectin coated on plastic resisted detachment by increasing shear forces. By comparing this result with an earlier study of the rolling of neutrophils on P-selectin incorporated into planar membranes (28), they concluded that flowing neutrophils attached with similar efficiency to P-selectin and E-selectin, but rolled with greater adhesive strength on Eselectin than on P-selectin (27). In direct comparisons, we instead found that flowing neutrophils attached more efficiently and with greater adhesive strength to P-selectin than to E-selectin. Furthermore, shear stress readily removed neutrophils adherent to both P- and E-selectin when expressed on CHO cells but not when coated on plastic. The mechanism by which plastic strengthens static adhesion of neutrophils to immobilized selectins is obscure, but is unlikely to be physiologically relevant. We therefore used selectin-expressing $\mathrm{CHO}$ cells for all other experiments described in this study.

We showed previously that the anti-PSGL-1 mAb PL1 abolishes adhesion of neutrophils to P-selectin under both static and shear conditions (25). Thus, PSGL-1 must bind to P-selectin for neutrophils to attach to and then roll on P-selectin under flow. However, the interactions of flowing neutrophils with Eselectin are more complex. In previous competitive binding experiments with purified molecules, E-selectin appeared to bind PSGL-1 at or near the principle recognition site for Pselectin, although with lower affinity $(11,25)$. The results are consistent with a model in which each subunit of PSGL-1 contains one epitope for PL1 that overlaps a common recognition site for P- and E-selectin. In this study, we found that PL1 only partially inhibited binding of purified PSGL-1 to immobilized E-selectin, suggesting that each subunit of PSGL-1 has one or more additional binding sites for E-selectin. The number and relative affinities of these sites are unknown. PL1 substantially inhibited the attachment of flowing neutrophils to E-selectin, indicating that the PL1-defined site on PSGL-1 is a major mediator of neutrophil attachment under shear stress. Flowing neutrophils may attach less efficiently to E-selectin than to P-selectin, at least in part, because of the lower affinity of the PL1defined recognition site for E-selectin than for P-selectin. Whether this lower affinity is due to a slower on-rate and/or a faster off-rate for binding requires further study. PL1 did not inhibit all attachment of flowing neutrophils to E-selectin, indicating that other recognition sites for E-selectin on PSGL-1 or on other molecules contribute to attachment under flow.

L-selectin has been proposed to mediate attachment of flowing neutrophils to both P- and E-selectin (19). Consistent with this model, mAbs to L-selectin partially inhibit rolling of neutrophils on both P- and E-selectin in some systems $(19,23$, 24). Lawrence et al. (22) reported that flowing neutrophils attached poorly to E-selectin-coated plastic if they were incubated with the anti-L-selectin mAb DREG-56 or if they shed L-selectin in response to activation. Such treatments had no effect if neutrophils first attached to E-selectin under static conditions and then were subjected to shear stress. The authors concluded that L-selectin is required for optimal attachment to E-selectin under shear conditions, but not for subsequent rolling on E-selectin. We observed that anti-PSGL-1 mAb PL1 abolished attachment of flowing neutrophils to P-selectin (25) and significantly inhibited attachment to E-selectin (this study). Thus, L-selectin alone does not mediate optimal attachment of neutrophils to either P- or E-selectin under shear stress. We also found that HL-60 cells lacking L-selectin rolled on both P- and E-selectin, and rolling was inhibited by PL1. Therefore, HL-60 cells can use PSGL-1 to attach to either P- or E-selectin under flow without a requirement for L-selectin. HL-60 cells roll even though flow cytometric analysis indicates that the number of PSGL-1-dependent binding sites for P-selectin is lower on HL-60 cells than on neutrophils (Moore, K. L., unpublished observations )

Unlike HL-60 cells, flowing neutrophils require the cooperative function of L-selectin and PSGL-1 to attach optimally to E-selectin. It is less clear whether flowing neutrophils use Lselectin for optimal attachment to P-selectin. In our experiments, DREG-56 consistently failed to inhibit attachment of flowing neutrophils to P-selectin, but inhibited attachment of the same neutrophils to E-selectin. A combination of PL1 and DREG-56 blocked attachment of flowing neutrophils to E-selectin more effectively than either individual antibody. Upon activation with FMLP, neutrophils shed L-selectin and failed to attach under shear to either E- or P-selectin, even in the presence of cytochalasin D to maintain their round shapes. It is unknown whether the inability of the cells to attach reflects activationinduced changes other than the shedding of L-selectin. We attempted to remove L-selectin from the cell surface with chymotrypsin $(19,22)$, but even very low concentrations of the enzyme also eliminated the PL1 and PL2 epitopes on PSGL-1 (Patel, K. D., unpublished observations).

L-selectin may augment attachment of flowing neutrophils by presenting a weak carbohydrate ligand for E-selectin (and perhaps P-selectin) (19). L-selectin may also indirectly promote neutrophil attachment to E-selectin through cis interactions with another ligand for E-selectin (22). PSGL-1 is a candidate for such a ligand. Both L-selectin and PSGL-1 are localized on the microvilli of resting neutrophils $(19,25,43,44)$. PSGL1 carries many O-linked glycans, some of which might interact with L-selectin. L-selectin may promote clustering of PSGL-1 on microvilli, enhancing its avidity for E-selectin. DREG-56 might disrupt such clustering, impairing rapid bond formation with E-selectin under flow. It is unknown whether PSGL-1 is organized differently in the membrane of HL-60 cells, which lack L-selectin.

In the absence of flow, DREG-56 (27) and PL1 (this study) did not inhibit adhesion of neutrophils to E-selectin, suggesting that other E-selectin-ligand interactions dominate under these conditions. It is unclear whether these are the same interactions that maintain rolling adhesions under continuous shear. Bonds might develop between E-selectin and the recognition site(s) on PSGL-1 that is unaffected by PL1. If this site( $\mathrm{s}$ ) is essential for adhesion, it must be proximal to the sites cleaved by OSGE, since treatment of HL-60 cells with the enzyme does not affect static adhesion to E-selectin (42 and Patel, K. D., unpublished observations). Bonds might also form with other neutrophil ligands for E-selectin such as the 150-kD E-selectin ligand-1 $(17,21)$. Whatever additional interactions form, neutrophils 
still roll with less adhesive strength on E-selectin than on Pselectin, as reflected by their higher rolling velocities on $\mathrm{E}$ selectin.

The cytoskeleton may regulate some adhesive functions of selectins or their ligands. Cytochalasin treatment of L-selectintransfected cells inhibits their adhesion to endothelial cells expressing carbohydrate ligands for L-selectin (45). In contrast, we found that neutrophils treated with cytochalasin D attached normally to both E-selectin and P-selectin under shear. These data suggest that most actin filaments are not required for $\mathrm{L}$ selectin and/or PSGL-1 to mediate attachment of resting neutrophils to E- or P-selectin under flow. In other studies, however, we observed that activation of neutrophils reduced their adhesion to P-selectin even under static conditions (46). The weakened adhesion was associated with a redistribution of PSGL1 -dependent binding sites for P-selectin to the uropods of the cells. Both the reduced adhesion and the redistribution of binding sites were prevented when the neutrophils were pretreated with cytochalasin D (46), suggesting that activation regulates the function of PSGL-1 through cytoskeletally dependent mechanisms.

The physiological significance of the superior attachment efficiency and adhesive strength of neutrophils rolling on Pselectin relative to E-selectin remains to be determined. We demonstrated previously that a specific recognition site for $\mathbf{P}$ selectin on PSGL-1 is essential for flowing neutrophils to attach to and roll on P-selectin (25). The current study indicates that a similar site on PSGL-1 functions cooperatively with L-selectin to mediate attachment of flowing neutrophils to E-selectin. After attachment, other binding sites for E-selectin on PSGL-1 and/ or on other molecules maintain adhesion. Differential mechanisms for attachment of neutrophils to P- and E-selectin may also allow differential signaling of the adherent cells (47-50).

\section{Acknowledgments}

We thank Cindy Carter and Ginger Hampton for excellent technica assistance, and the Office of Administrative and Scientific Information Systems at the Oklahoma Medical Research Foundation for secretarial assistance. We also thank James Morrissey and Guy Zimmerman for critical review of the manuscript and Andrew Weyrich for assaying the LPS concentrations in the PL1 and PL2 mAbs.

This research was supported in part by grant HL-45510 (R. P. McEver and K. L. Moore) from the U. S. Public Health Service. Dr. Patel is a recipient of a National Research Service Award (HL-09035) from the National Institutes of Health. Dr. Moore is a recipient of a Clinician Scientist Award (900403) from the American Heart Association with funds contributed in part by the AHA Oklahoma Affiliate.

\section{References}

1. McEver, R. P., K. L. Moore, and R. D. Cummings. 1995. Leukocyte trafficking mediated by selectin-carbohydrate interactions. J. Biol. Chem 270:11025-11028.

2. Lasky, L. A. 1992. Selectins: interpreters of cell-specific carbohydrate information during inflammation. Science (Wash. DC). 258:964-969.

3. McEver, R. P. 1994. Selectins. Curr. Opin. Immunol. 6:75-84.

4. Zimmerman, G. A., S. M. Prescott, and T. M. McIntyre. 1992. Endothelial cell interactions with granulocytes: tethering and signaling molecules. Immunol. Today. 13:93-100.

5. Jutila, M. A., R. F. Bargatze, S. Kurk, R. A. Warnock, N. Ehsani, S. R. Watson, and B. Walcheck. 1994. Cell surface P- and E-selectin support sheardependent rolling of bovine $\gamma / \delta \mathrm{T}$ cells. J. Immunol. 153:3917-3928.

6. Jones, D. A., L. V. McIntire, C. W. Smith, and L. J. Picker. 1994. A two-step adhesion cascade for $\mathrm{T}$ cell/endothelial cell interactions under flow conditions. $J$. Clin. Invest. 94:2443-2450.
7. Alon, R., H. Rossiter, X. Wang, T. A. Springer, and T. S. Kupper. 1994. Distinct cell surface ligands mediate $\mathrm{T}$ lymphocyte attachment and rolling on $\mathrm{P}$ and E-selectin under physiological flow. J. Cell Biol. 127:1485-1495.

8. Berlin, C., R. F. Bargatze, J. J. Campbell, U. H. Von Andrian, M. C. Szabo, S. R. Hasslen, R. D. Nelson, E. L. Berg, S. L. Erlandsen, and E. C. Butcher. 1995. $\alpha 4$ integrins mediate lymphocyte attachment and rolling under physiologic flow. Cell. 80:413-422.

9. Alon, R., P. D. Kassner, M. W. Carr, E. B. Finger, M. E. Hemler, and T. A. Springer. 1995. The integrin VLA-4 supports tethering and rolling in flow on VCAM-1. J. Cell Biol. 128:1243-1253. 7397.

10. Varki, A. 1994. Selectin ligands. Proc. Natl. Acad. Sci. USA. 91:7390-

11. Moore, K. L., S. F. Eaton, D. E. Lyons, H. S. Lichenstein, R. D. Cummings, and R. P. McEver. 1994. The P-selectin glycoprotein ligand from human neutrophils displays sialylated, fucosylated, $O$-linked poly- $N$-acetyllactosamine. J. Biol. Chem. 269:23318-23327.

12. Sako, D., X.-J. Chang, K. M. Barone, G. Vachino, H. M. White, G. Shaw, G. M. Veldman, K. M. Bean, T. J. Ahern, B. Furie, et al. 1993. Expression cloning of a functional glycoprotein ligand for P-selectin. Cell. 75:1179-1186.

13. Norgard, K. E., K. L. Moore, S. Diaz, N. L. Stults, S. Ushiyama, R. P. McEver, R. D. Cummings, and A. Varki. 1993. Characterization of a specific ligand for P-selectin on myeloid cells. A minor glycoprotein with sialylated Olinked oligosaccharides. J. Biol. Chem. 268:12764-12774.

14. Baumhueter, S., M. S. Singer, W. Henzel, S. Hemmerich, M. Renz, S. D. Rosen, and L. A. Lasky. 1993. Binding of L-selectin to the vascular sialomucin CD34. Science (Wash. DC). 262:436-438.

15. Berg, E. L., L. M. McEvoy, C. Berlin, R. F. Bargatze, and E. C. Butcher. 1993. L-selectin-mediated lymphocyte rolling on MAdCAM-1. Nature (Lond.). 366:695-698.

16. Lenter, M., A. Levinovitz, S. Isenmann, and D. Vestweber. 1994. Monospecific and common glycoprotein ligands for E- and P-selectin on myeloid cells. J. Cell Biol. 125:471-481.

17. Steegmaler, M., A. Levinovitz, S. Isenmann, E. Borges, M. Lenter, H. P. Kocher, B. Kleuser, and D. Vestweber. 1995. The E-selectin-ligand ESL-1 is a variant of an FGF-receptor. Nature (Lond.). 373:615-620.

18. Walcheck, B., G. Watts, and M. A. Jutila. 1993. Bovine $\gamma / \delta$ T cells bind E-selectin via a novel glycoprotein receptor: first characterization of a lymphocyte/ E-selectin interaction in an animal model. J. Exp. Med. 178:853-863.

19. Picker, L. J., R. A. Warnock, A. R. Burns, C. M. Doerschuk, E. L. Berg, and E. C. Butcher. 1991. The neutrophil selectin LECAM-1 presents carbohydrate ligands to the vascular selectins ELAM-1 and GMP-140. Cell. 66:921-933.

20. Moore, K. L., A. Varki, and R. P. McEver. 1991. GMP-140 binds to a glycoprotein receptor on human neutrophils: evidence for a lectin-like interaction. J. Cell Biol. 112:491-499.

21. Levinovitz, A., J. Mühlhoff, S. Isenmann, and D. Vestweber. 1993. Identification of a glycoprotein ligand for E-selectin on mouse myeloid cells. J. Cell Biol. 121:449-459.

22. Lawrence, M. B., D. F. Bainton, and T. A. Springer. 1994. Neutrophil tethering to and rolling on E-selectin are separable by requirement for $\mathrm{L}$-selectin. Immunity. 1:137-145.

23. Jones, D. A., O. Abbassi, L. V. McIntire, R. P. McEver, and C. W. Smith. 1994. P-selectin mediates neutrophil rolling on histamine-stimulated endothelial cells. Biophys. J. 65:1560-1569.

24. Buttrum, S. M., R. Hatton, and G. B. Nash. 1993. Selectin-mediated rolling of neutrophils on immobilized platelets. Blood. 82:1165-1174.

25. Moore, K. L., K. D. Patel, R. E. Bruehl, L. Fugang, D. A. Johnson, H. S. Lichenstein, R. D. Cummings, D. F. Bainton, and R. P. McEver. 1995. P-selectin glycoprotein ligand-1 mediates rolling of human neutrophils on P-selectin. J. Cell Biol. 128:661-671.

26. Moore, K. L., N. L. Stults, S. Diaz, D. L. Smith, R. D. Cummings, A Varki, and R. P. McEver. 1992. Identification of a specific glycoprotein ligand for P-selectin (CD62) on myeloid cells. J. Cell Biol. 118:445-456.

27. Lawrence, M. B., and T. A. Springer. 1993. Neutrophils roll on E-selectin. J. Immunol. 151:6338-6346.

28. Lawrence, M. B., and T. A. Springer. 1991. Leukocytes roll on a selectin at physiologic flow rates: distinction from and prerequisite for adhesion through integrins. Cell. 65:859-873.

29. Moore, K. L. 1994. Purification of P-selectin (CD62P) from human platelets. J. Tissue Culture Methods. 16:1-3.

30. Ushiyama, S., T. M. Laue, K. L. Moore, H. P. Erickson, and R. P. McEver. 1993. Structural and functional characterization of monomeric soluble P-selectin and comparison with membrane P-selectin. J. Biol. Chem. 268:15229-15237.

31. McEver, R. P., and M. N. Martin. 1984. A monoclonal antibody to a membrane glycoprotein binds only to activated platelets. J. Biol. Chem. 259:9799-9804.

32. Geng, J.-G., M. P. Bevilacqua, K. L. Moore, T. M. McIntyre, S. M. Prescott, J. M. Kim, G. A. Bliss, G. A. Zimmerman, and R. P. McEver. 1990. Rapid neutrophil adhesion to activated endothelium mediated by GMP-140. $\mathrm{Na}$ ture (Lond.). 343:757-760. 
33. Johnston, G. I., A. Kurosky, and R. P. McEver. 1989. Structural and biosynthetic studies of the granule membrane protein, GMP-140, from human platelets and endothelial cells. J. Biol. Chem. 264:1816-1823.

34. Hamburger, S. A., and R. P. McEver. 1990. GMP-140 mediates adhesion of stimulated platelets to neutrophils. Blood. 75:550-554.

35. Mulligan, M. S., J. Varani, M. K. Kame, C. L. Lane, C. W. Smith, D. C. Anderson, and P. A. Ward. 1991. Role of endothelial-leukocyte adhesion molecule 1 (ELAM-1) in neutrophil-mediated lung injury in rats. J. Clin. Invest. 88:13961406.

36. Kishimoto, T. K., M. A. Jutila, and E. C. Butcher. 1990. Identification of a human peripheral lymph node receptor: A rapidly down-regulated adhesion receptor. Proc. Natl. Acad. Sci. USA. 87:2244-2248.

37. Wright, S. D., P. E. Rao, W. C. Van Voorhis, L. S. Craigmyle, K. Iida, M. A. Talle, E. F. Westberg, G. Goldstein, and S. C. Silverstein. 1983. Identification of the C3bi receptor of human monocytes and macrophages by using monoclonal antibodies. Proc. Natl. Acad. Sci. USA. 80:5699-5703.

38. Esmon, C. T., N. L. Esmon, B. F. Le Bonniec, and A. E. Johnson. 1993. Protein C activation. Methods Enzymol. 222:359-385.

39. Zimmerman, G. A., T. M. McIntyre, and S. M. Prescott. 1985. Thrombin stimulates the adherence of neutrophils to human endothelial cells in vitro. $J$. Clin. Invest. 76:2235-2246.

40. Bevilacqua, M. P., S. Stengelin, M. A. Gimbrone, Jr., and B. Seed. 1989. Endothelial leukocyte adhesion molecule 1: an inducible receptor for neutrophils related to complement regulatory proteins and lectins. Science (Wash. DC). 243:1160-1165.

41. Sutherland, D. R., K. M. Abdullah, P. Cyopick, and A. Mellors. 1992. Cleavage of the cell-surface $O$-sialoglycoproteins CD34, CD43, CD44, and CD45 by a novel glycoprotease from Pasturella hemolytica. J. Immunol. 148:14581464.

42. Steininger, C. N., C. A. Eddy, R. M. Leimgruber, A. Mellors, and J. K. Welply. 1992. The glycoprotease of Pasteurella haemolytica A1 eliminates bind- ing of myeloid cells to P-selectin but not to E-selectin. Biochem. Biophys. Res. Commun. 188:760-766.

43. Borregaard, N., L. Kjeldson, H. Sengelov, M. S. Diamond, T. A. Springer, H. C. Anderson, T. K. Kishimoto, and D. F. Bainton. 1994. Changes in subcellular localization and surface expression of L-selectin, alkaline phosphatase, and Mac1 in human neutrophils during stimulation with inflammatory mediators. J. Leukocyte Biol. 56:80-87.

44. Erlandsen, S. L., S. R. Hasslen, and R. D. Nelson. 1993. Detection and spatial distribution of the $\beta_{2}$ integrin (Mac-1) and L-selectin (LECAM-1) adherence receptors on human neutrophils by high-resolution field emission SEM. $J$. Histochem. Cytochem. 41:327-333.

45. Kansas, G. S., K. Ley, J. M. Munro, and T. F. Tedder. 1993. Regulation of leukocyte rolling and adhesion to high endothelial venules through the cytoplasmic domain of L-selectin. J. Exp. Med. 177:833-838.

46. Lorant, D. E., R. P. McEver, T. M. McIntyre, K. L. Moore, S. M. Prescott, and G. A. Zimmerman. 1995. Activation of polymorphonuclear leukocytes reduces their adhesion to P-selectin and causes redistribution of ligands for Pselectin on their surfaces. J. Clin. Invest. 96:171-182.

47. Lorant, D. E., K. D. Patel, T. M. McIntyre, R. P. McEver, S. M. Prescott, and G. A. Zimmerman. 1991. Coexpression of GMP-140 and PAF by endothelium stimulated by histamine or thrombin: a juxtacrine system for adhesion and activation of neutrophils. J. Cell Biol. 115:223-234.

48. Lorant, D. E., M. K. Topham, R. E. Whatley, R. P. McEver, T. M. McIntyre, S. M. Prescott, and G. A. Zimmerman. 1993. Inflammatory roles of Pselectin. J. Clin. Invest. 92:559-570.

49. Cooper, D., C. M. Butcher, M. C. Berndt, and M. A. Vadas. 1994. Pselectin interacts with a $\beta_{2}$-integrin to enhance phagocytosis. J. Immunol. 153:3199-3209.

50. Lo, S. K., S. Lee, R. A. Ramos, R. Lobb, M. Rosa, G. Chi-Rosso, and S. D. Wright. 1991. Endothelial-leukocyte adhesion molecule 1 stimulates the adhesive activity of leukocyte integrin CR3 (CD11b/CD18, Mac-1, $\left.\alpha_{\mathrm{m}} \beta_{2}\right)$ on human neutrophils. J. Exp. Med. 173:1493-1500. 